\title{
MANAGING A FIRM'S CASH FLOW RECOVERY STRATEGY
}

Tepper Working Paper 2011-E26

Aditya V. Rajkumar arajkuma@tepper.cmu.edu

Jeffrey R.Williams jrw@cmu.edu

July 2011

Tepper School of Business at Carnegie Mellon

Pittsburgh, PA 15213

The authors gratefully acknowledge the advice and suggestions received from Burton Hollifield and Pierre Jinghong Liang in the pursuit of this project. 


\title{
MANAGING A FIRM'S CASH FLOW RECOVERY STRATEGY
}

\begin{abstract}
Traditional cash flow estimation techniques focus on generating net cash flow estimates period-by-period, which are then discounted by the firm's cost of capital. While conceptually strong, this aggregation approach can be insensitive to the fine-grained detail so important to managing project cash flows, in particular, that investment returns are always a combination of growth (renewal) and decline (convergence) forces at work over the firm's life. As is demonstrated in this paper, the aggregation problem can be addressed by employing a cash flow recovery period (CFRP) framework, which distinguishes and quantifies the renewal and convergence forces unique to each firm's project cash flows. The benefit of this more fine-grained approach is that it provides an additional level of detail that can be used to manage firm returns.
\end{abstract}




\section{MANAGING A FIRM'S CASH FLOW RECOVERY STRATEGY}

\section{INTRODUCTION}

Valuation using discounted cash flows is considered both an art and a science. Current forecasting techniques use various techniques to determine future forecasts. However, such techniques, lacking strategic frameworks, often provide little explicit linkage to the forces that drive forecasted values, nor do they provide direct reasoning as to why forecasted cash flows increase or decrease. In contrast, a strategic framework that explicitly links competitive forces to cash flow estimates would be useful in more precisely quantifying and managing the value created by firms over time. Taking inspiration from work done by Rappaport (1987), Rizzi (1984), Day and Fahey (1988) and Christopher (1999), we have examined the link between strategy and firm value and have developed a cash flow recovery period (CFRP) valuation framework.

As we will show, one could expect considerable benefits for a firm to adopt such a framework. First, such a structure would potentially encourage more accurate forecasting, by linking the dynamic competitive forces at work in the firm's environment to actual cash flows that result. Second, the framework would provide a forward-looking cause and effect explanation to its forecasts that would enable the user to develop executable strategies over time that enhance firm value. Finally, such a framework could help calculate the amount of value being created by different strategic options under consideration by the firm.

In order to build such a framework, we first identify principles of competitive strategy that can be aligned with valuation techniques. Once these links are identified, we develop a strategic framework, based on CFRP principles, to address these links and make adjustments to valuation equations to incorporate missing elements. As a final goal of this paper, we illustrate via simulation how valuation estimates using the CFRP framework yield increased precision and accuracy.

\section{BUILDING STRATEGY INTO THE PERPETUITY ASSUMPTION}

While different methods of valuation define a firm's lifecycle differently, they all contain certain drawbacks. The most popular variant of intrinsic valuation, the discounted cash flow method, is characterized by the emphasis it places on the perpetuity part of the valuation. As stated in the first Miller-Modigliani paper, "Dividend Policy, Growth, and the Valuation of Shares", MillerModigliani (1961), the value of a company is equal to the time discounted summation of all future cash flows generated by that company. The discounted cash flow (DCF) method is made up of two sections. The first is a sum of discounted cash flows over a transient, short time period. 
The second is the perpetuity value of cash flows generated by the firm as a going concern. One of the drawbacks when using a DCF model is the high percentage of value trapped in the estimate of perpetuity as compared to the transient time period (Mauboussin, 1997).

To calculate the perpetuity value one can either use the Gordon growth method, which uses an adjusted equation derived by Gordon (1959), or the exit multiple approach. In the Gordon growth method, it is assumed that the company will continue to grow at a stable fixed growth rate to perpetuity. Unfortunately, the growth rate assumed is somewhat arbitrary with a single constraint of not exceeding the US economy growth rate. The exit multiple approach attempts to value the perpetuity value of the company relative to a market financial multiple such as Enterprise Value / EBITDA. Unfortunately, this method inherently contains the limitations of relative valuation such as sensitivity to macro economic factors. This significantly reduces one of the major advantages of DCF (being an intrinsic method where value of the company is calculated based on internal factors of the company and not external market conditions). Additionally, DCF valuation does not take into account the cyclic nature of competition, and competitive strategy, Rizzi (1984).

The value driver model (VDM) Stewart (1991), although logically similar to DCF, addresses the perpetuity dilemma and is somewhat more in line with strategy thinking. The VDM splits value creation between value generated from current operational earnings (NOPAT) until perpetuity and value generated from future potential NOPAT earnings created by investing capital, I, in projects with return ROIC greater than the cost of capital $\mathrm{C}$ for a time period $\mathrm{T}$. In practice, based on the type, maturity, and complexity of the industry, one then assumes an appropriate value of $\mathrm{T}$. Although this method brings finance estimates foundationally closer to competitive dynamics, there is still an issue with the static conceptualization of T. VDM defines T as a period of time during which a company earns excess returns (excess returns defined as ROIC - Cost of Capital). Once this time period, $\mathrm{T}$, has run out, the company cannot earn returns greater than the cost of capital.

Mauboussin has investigated $\mathrm{T}$ defined as "Competitive Advantage Period" in his paper "Competitive Advantage Period: The Neglected Driver", Mauboussin (1997). As compared to the VDM model, Mauboussin defines the Competitive Advantage Period or CAP as the market's estimation of the amount of time the company can generate excess returns. Therefore, as time progresses, the CAP need not gradually decrease but can remain constant or even increase based on market conditions. This can be achieved through outstanding management, acquisitions, etc. Mauboussin defines several factors that affect $\mathrm{T}$, which include return on invested capital (ROIC), rapidly changing industry conditions, and barriers to entry. Mauboussin emphasizes that companies with higher ROIC are best positioned competitively (reflecting scale economies, entry barriers, and management execution), and that it takes more time and effort to take away advantage from these companies. In his view, companies with higher ROIC have longer competitive advantage periods. This is in line with strategic theory as advocated by Rumelt, who postulates that firms with higher levels of profitability in stable markets possess difficult to imitate skills that deter competition (Rumelt 1984). While these positions are a step forward from the VDM, with its static concept of T, they do not provide insight or granularity into the causal factors that affect (or can be used to increase) CAP or T.

Since we did not find an adequate definition of a firm's lifecycle from a valuation perspective, we shift our focus to a strategy perspective. The principles of competitive cycles are explicit in Williams $(1993,1998)$. Here, markets are delineated by the "half life" of firm cash flows, and 
This model divides the free cash flows (FCF's) into two separate sections. The FCF that is generated from current NOPAT and the FCF generated in the future due to future increases in NOPAT. The FCF generated from future NOPAT grows due to investment of capital I into projects that have a return equal to (ROIC $-\mathrm{C}$ ). These excess returns translate into growth of NOPAT during time $\mathrm{T}$ that in turn grows FCF. FCF is equal to NOPAT less investment I during the period T. After period T, FCF is equal to NOPAT as there is no more additional capital investment. The first diagram on the left side of the page below is the graphical depiction of the amount of FCF and NOPAT created by a firm under the traditional value driver model. We have assumed the tax rate to be zero, and a constant cost of capital and investment amount per time period.

The diagram illustrates the main assumptions in the traditional model. First, the amount of excess returns generated remain constant at $(\mathrm{ROIC}-\mathrm{C})$ during time $\mathrm{T}$, depicted by the straight-line growth of NOPAT over time. After a given time $\mathrm{T}$, the company stops producing abnormal returns illustrated by the discontinuity in the NOPAT function at time T. Last, after time $\mathrm{T}$, the firm will not be able to renew its ability to create excess returns. Each time period for analysis has been defined by $\tau$, which shall equal to 1 year in the entire paper.

However, a more realistic assumption is that competitive advantage is lost gradually over time through the principle of convergence. If one modifies the traditional binary assumption to take into account steady excess return erosion, the result mirrors a decrease in competitive advantage over time. This linear decrease in (ROIC $-\mathrm{C}$ ) translates into a nonlinear function for NOPAT during time T. Second, once we move away from the instantaneous loss in excess return production, the NOPAT function loses its discontinuity at time $\mathrm{T}$ and becomes a completely continuous function. These two differences in assumptions are shown in the diagram placed to the right. We will further modify this diagram to account for renewal later in the paper.
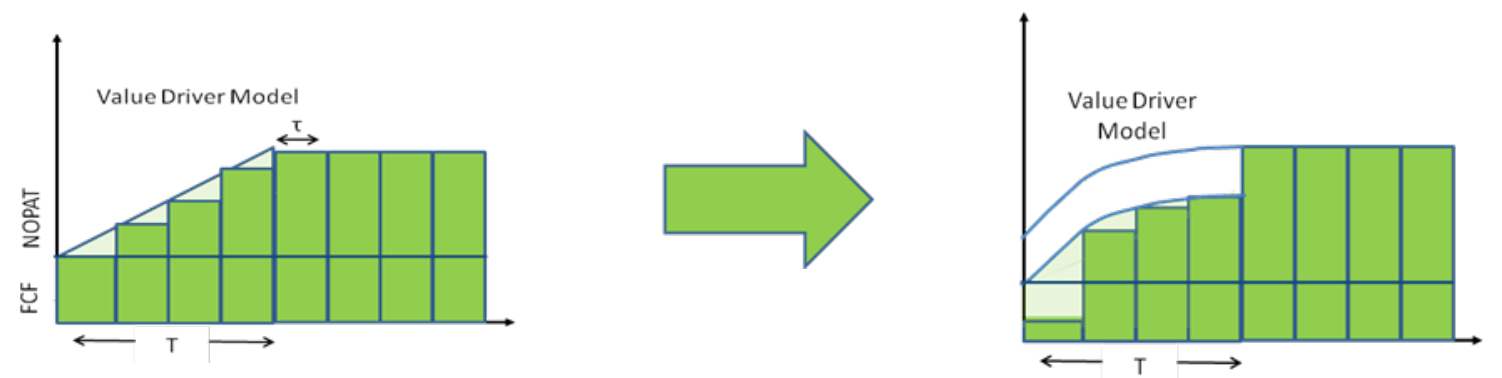

The above mentioned dynamics of a firm's NOPAT are hard to visualize due to their non linear nature, so we will translate the above diagrams into their Economic Value Added or EVA equivalents in order to develop linear equivalents of the above NOPAT digrams and equations. It is important to note that the two methods (EVA and VDM) are completely equivalent from a numerical valuation point of view (Shrieves 2001).

EVA is equal to the net present value of all the economic profit generated by the company over the period of its life.

$$
V=N O A+\sum_{n=1}^{T} \frac{\left(\text { ROI }_{n}-C_{n}\right)}{\left(1+C_{N}\right)^{n}} I_{n}
$$


$\mathrm{V}=$ Enterprise Value

NOA $=$ Net Operating Assets

$\mathrm{C}=$ Cost of Capital

$\mathrm{N}=$ year

ROIC $=$ Return on Invested Capital

$\mathrm{T}=$ Time Period during which investment is made

$\mathrm{I}=$ Investment in Time T

We have redrawn the above VDM diagrams using (ROIC - C), and not NOPAT, on the y-axis. Consequently, the first diagram on the left has the same three assumptions mentioned above; constant excess returns $(\mathrm{ROIC}-\mathrm{C}$ ) till $\mathrm{T}$; instantaneous loss of excess return $(\mathrm{ROIC}-\mathrm{C})$ at $\mathrm{T}$; and no renewal after $\mathrm{T}$. The diagram on the right contains the modified adjustment of having a steady erosion of excess return (ROIC $-\mathrm{C}$ ) till $\mathrm{T}$. This is has been graphically depicted by a decreasing linear function of excess return $(\mathrm{ROIC}-\mathrm{C})$ till $\mathrm{T}$.
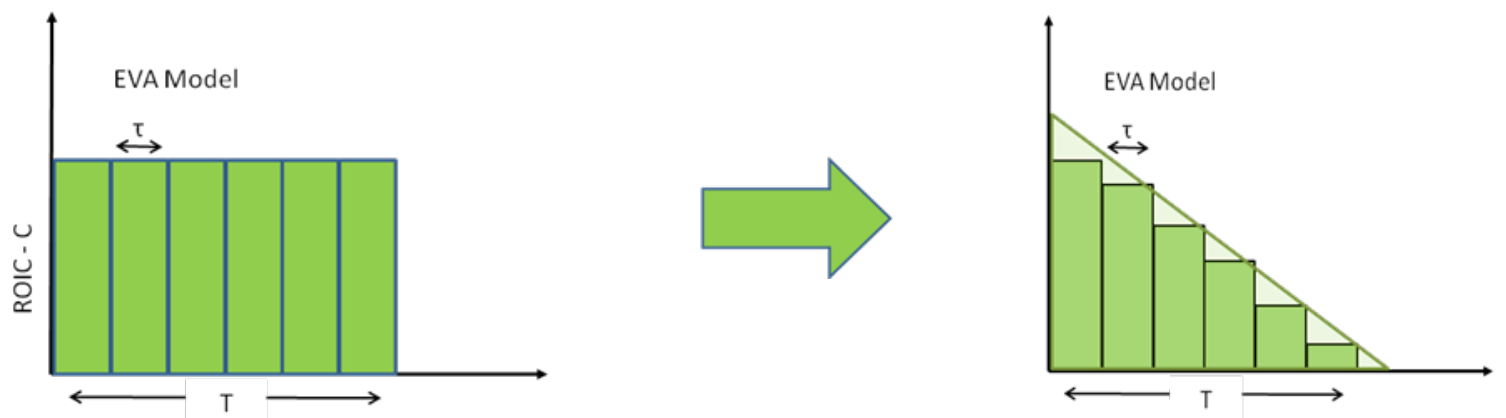

We now adjust the above diagrams to account for the possibility of renewal of excess returns (ROIC - C) post T. For symplicity we assume that renewal happens instantaneously for the firm's project. Using the concept of renewal, subsequent convergence, and the cyclic nature of competition, the following cycle is assumed to go on for pertuity. This is graphically represented in the diagram below.

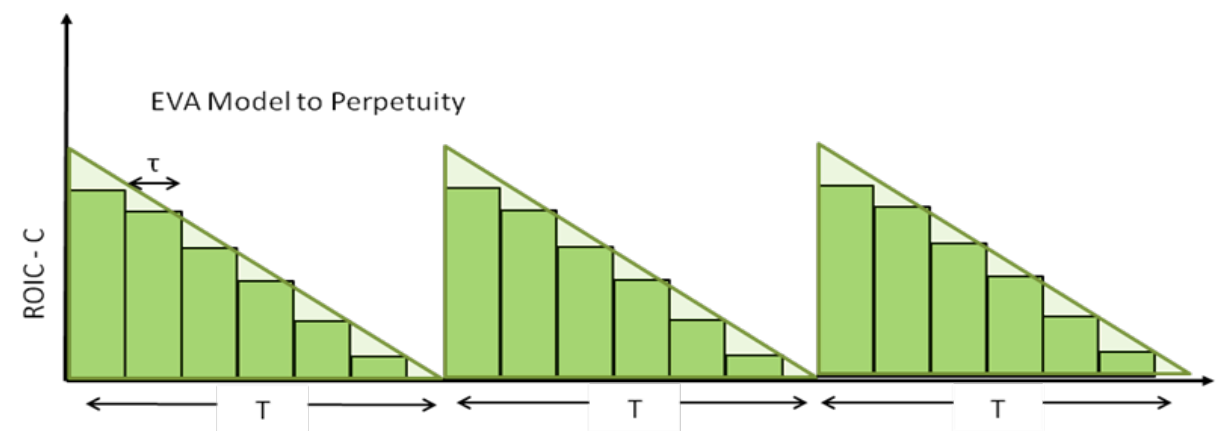

However, the assumption of instantaneous renewal is as unrealistic as instantaneous convergence and therefore needs to be relaxed. The diagram below shows the evolution of the graphical EVA model from one of instantaneous renewal to one of constant steady increase in excess return $(\mathrm{ROIC}-\mathrm{C})$ leading to renewal. 

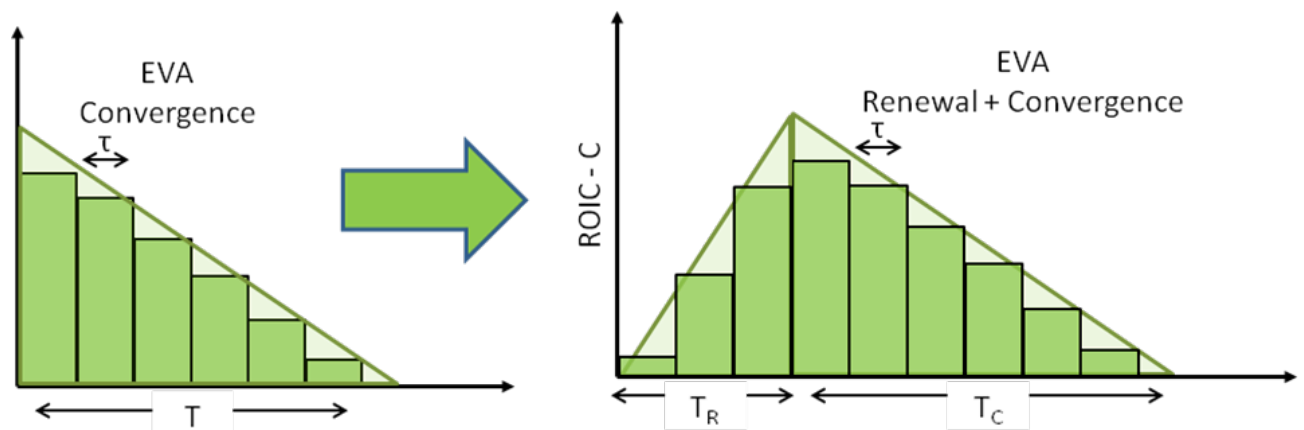

In this way, the cash flow recovery period (CFRP) is made up of two time periods, $T_{R}$ and $T_{C}$. $T_{R}$ is the renewal term of the cash flow recovery period and $T_{C}$ is the convergence term of the cash flow recovery period. Therefore, under the CFRP framework, the lifecycle of a firm in perpetuity, with continuous renewal and convergence, would look like the diagram below:

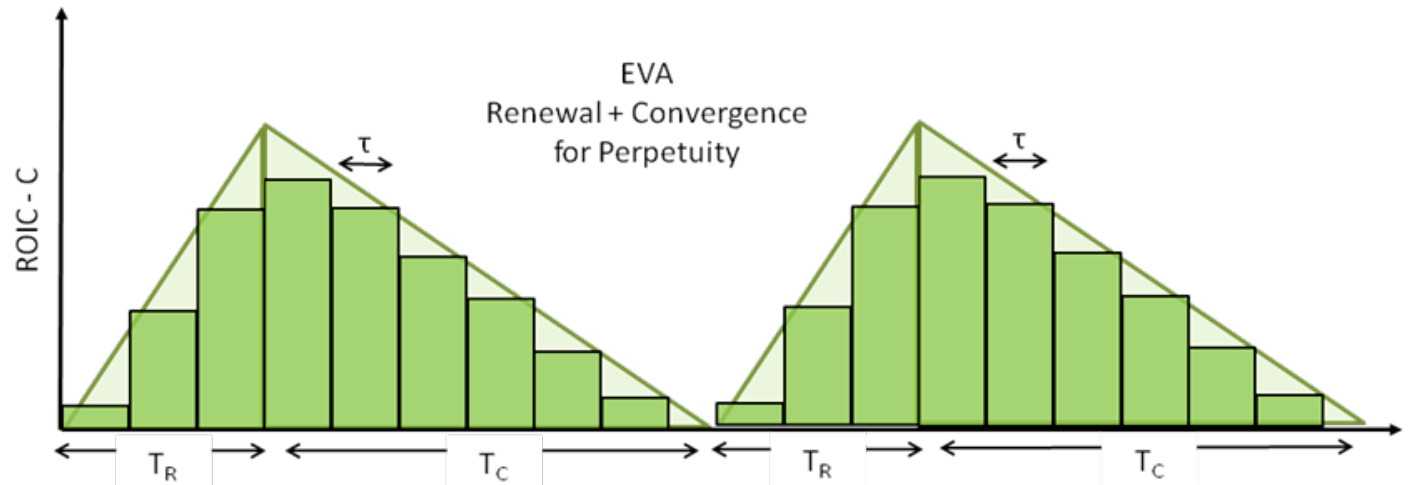

In summary, the following adjustments were made to the assumptions in a traditional EVA valuation model ${ }^{\mathrm{i}}$ in order to align it with principles of competitive cycles.

1. The period of renewal does not happen instantaneously but rather over a finite period of time.

2. A firm's excess returns or (ROIC - C), is not constant till $\mathrm{T}$ and zero after $\mathrm{T}$, but instead declines to zero at a constant rate.

3. A firm once in convergence will renew itself to produce excess returns that will also converge over time.

4. This cyclical nature of renewal and convergence is assumed to take place to perpetuity.

Consequently, the CFRP framework assumes that the lifecycle of a firm can be described by an infinite saw-tooth function, comprised of $T_{R}$ or Renewal periods and $T_{C}$ or Convergence periods. These renewal and convergence periods are defined as linear functions of excess return (ROIC C). Using these equations, the area under the curve could be calculated as the total amount of economic value added to perpetuity. By calculating the net present value of this economic value added, the valuation of the firm or project can be determined with more precision with respect to renewal and convergence strategies. 
To illustrate the use of this framework we now go into more detail as to the components of renewal and convergence forces and their underlying strategies. Renewal can be thought of as the comprehensive list of activities undertaken by a firm in order to regenerate its competitive advantage, thereby generating excess returns through increases in return on capital invested. We have assumed that these ROIC renewal forces increase the excess returns of the firm (ROIC - C) at a constant rate. Therefore, the term (ROIC - C) is a straight line with positive slope. The rate of increase in excess return can be termed as the firm's net growth function, $\mathrm{M}_{\mathrm{rnet}}$. Using $\mathrm{C}$ or $\mathrm{y}$ intercept $=0$, we get the equation:

$(R O I C-C)=M_{\text {rnet }} \mathrm{T}_{\mathrm{R}}$

Net growth function, $\mathrm{M}_{\text {rnet }}=$

$M_{\text {rnet }}=\frac{(R O I C-C)_{\max }}{T_{R}}$

The net growth function $\mathrm{M}_{\text {rnet }}$ determines the rate of increase in

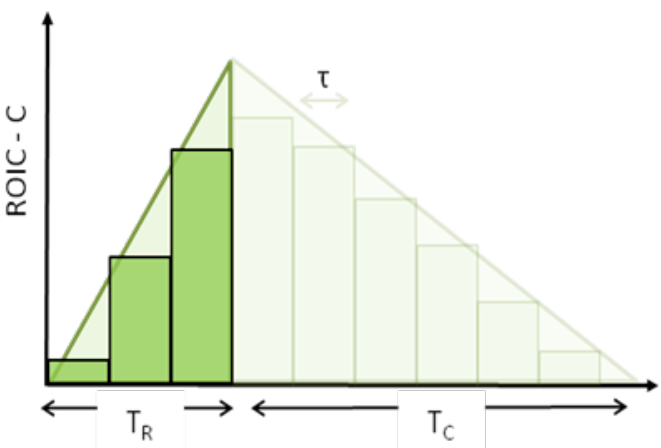
excess returns for the project or firm.

$\mathrm{M}_{\text {rnet }}$ can also be thought of as the rate of growth of excess returns over time due to competitive strategies. Mathematically this can be shown in the following manner:

$1^{\text {st }}$ Derivative:

$\frac{d y}{d t}=\lim _{\Delta t \rightarrow \infty} \frac{\Delta y}{\Delta t}=\lim _{\Delta t \rightarrow \infty} \frac{M_{\text {rnet }}(t+1)-M_{\text {rnet }}(t)}{\Delta t}$

$\lim _{\Delta t \rightarrow \infty} \frac{M_{r n e t} \Delta t}{\Delta t}=M_{r n \theta t}$

As $\Delta t$ approaches $0, \mathrm{M}_{\text {rnet }}$ becomes the first derivative of excess returns with respect to time.

The net growth function $\mathrm{M}_{\mathrm{rnet}}$ is defined by the magnitude of the maximum excess return (ROIC C) $)_{\max }$ generated by the firm and the amount of time it takes to achieve that return, $T_{R}$. As discussed before, the return (ROIC - C) max $_{\text {ax }}$ that is actually realized is reduced by the forces of convergence that reduce excess returns over time. By assumption, these forces of convergence only affect the magnitude of excess returns and therefore do not interfere with renewal time $T_{R}$. We can convert these forces into mathematical slope functions: $M_{\text {rnet }}$, net growth function; $M_{r}$,

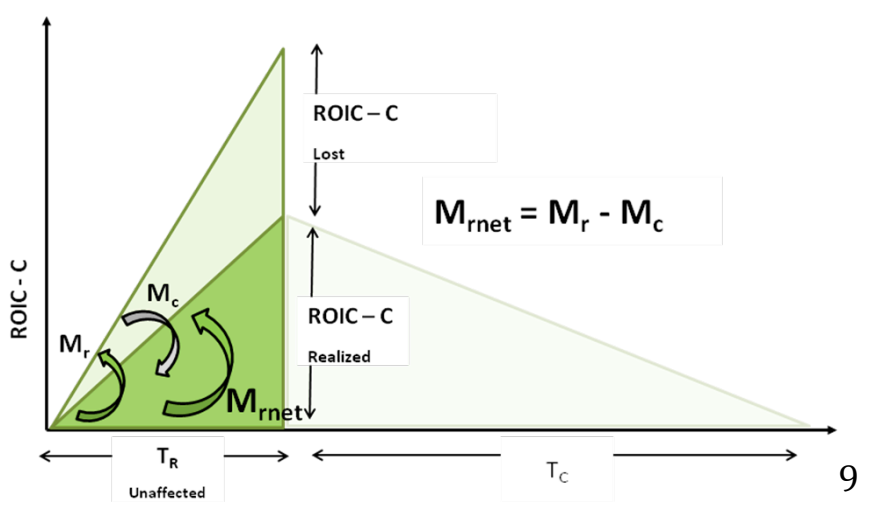
renewal function; and $\mathrm{M}_{\mathrm{c}}$, decay function.

The renewal function $M_{r}$ accounts for excess returns and the decay function $\mathrm{M}_{\mathrm{c}}$ reflects forces working to reduce excess returns over time. As stated before, the decay function, $M_{c}$ acts on the project in both time periods, renewal, $T_{R}$ and convergence, $\mathrm{T}_{\mathrm{C}}$ because the competitive 
forces driving the decay function are assumed to be present in both time periods $T_{R}$ and $T_{C}$ (Further discussion on the forces driving the decay function is done in the convergence section).

$\mathrm{M}_{\mathrm{r}}$ depends on the forces of renewal to drive growth in (ROIC $-\mathrm{C}$ ) as well as competitive learning forces that determine renewal time, $T_{R}$. Barnett, in his paper "Red Queen in Organizational Evolution" has discussed several learning forces that affect the competitive learning experiences of a firm and its effect on competitive reaction time (Barnett 1996). Of the

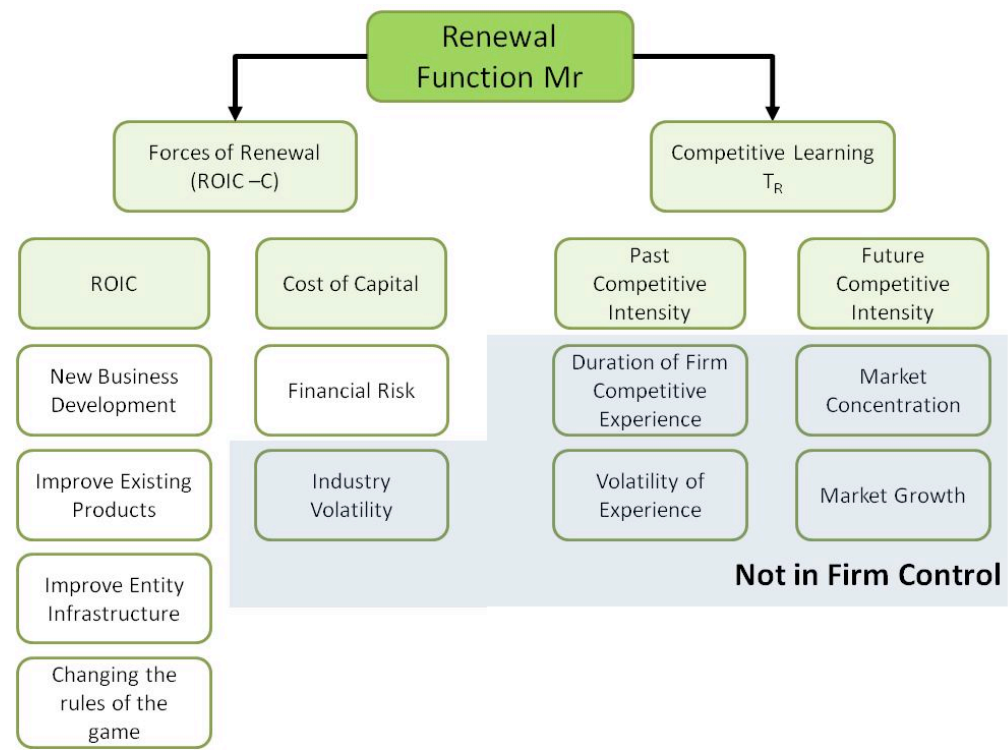
forces identified by Barnett, we postulate that intensity of the firm's competitive experience, as defined by length of experience and volatility in experience, affects the renewal function $\mathrm{M}_{\mathrm{r}}$. The more intense a firm's competitive experience, the more efficient is its competitive reaction time, thereby increasing $\mathrm{M}_{\mathrm{r}}$ by reducing renewal time $T_{R}$.

Derfus, in the paper "The Red Queen Effect: Competitive Actions and Firm Performance", has defined "moderators of the Red Queen Effect" (Derfus 2008). We interpret these moderators as factors that determine the intensity of future competitive experiences. Specifically, market concentration tends to increase intensity of future competition, thereby reducing competitive reaction time and reducing renewal time $T_{R}$. Market growth tends to dilute future competitive intensity and therefore increasing competitive reaction time and renewal time $T_{R}$. At the same time, the intensity of a firm's competitive experience is not in the firm's control but is based on external industry and circumstantial factors. For our purposes here, we focus on the forces of renewal that are under the firm's control, specifically, forces that cause an increase in ROIC rather than a decrease in the cost of capital. (The drivers of cost of capital, such as industry volatility and risk, are outside the firm's control. The other driver, financial risk, can be assumed to have been optimized to balance the loss from financial risk and gains from tax shields.)

With respect to the renewal forces that drive the renewal function $\mathrm{M}_{\mathrm{r}}$, we decompose ROIC into its various renewal components using the classic DuPont formulation:

ROIC $=P M \times A T O \gg \frac{\text { Profit }}{\text { Sales }} \times \frac{\text { Sales }}{\text { Assets }} \gg \frac{\text { Sales }- \text { Op_Costs }}{\text { Sales }} \times \frac{\text { Price } \times \text { Volume }}{\text { Assets }}$

Therefore the renewal function is given by

$m_{r}=f\left(S_{f}, P M_{f}, C B_{f}\right)$ where: $\mathrm{S}_{\mathrm{F}}=$ Sales, $\mathrm{PM}_{\mathrm{F}}=$ Profit Margin, $\mathrm{CB}_{\mathrm{F}}=$ Capital Base 


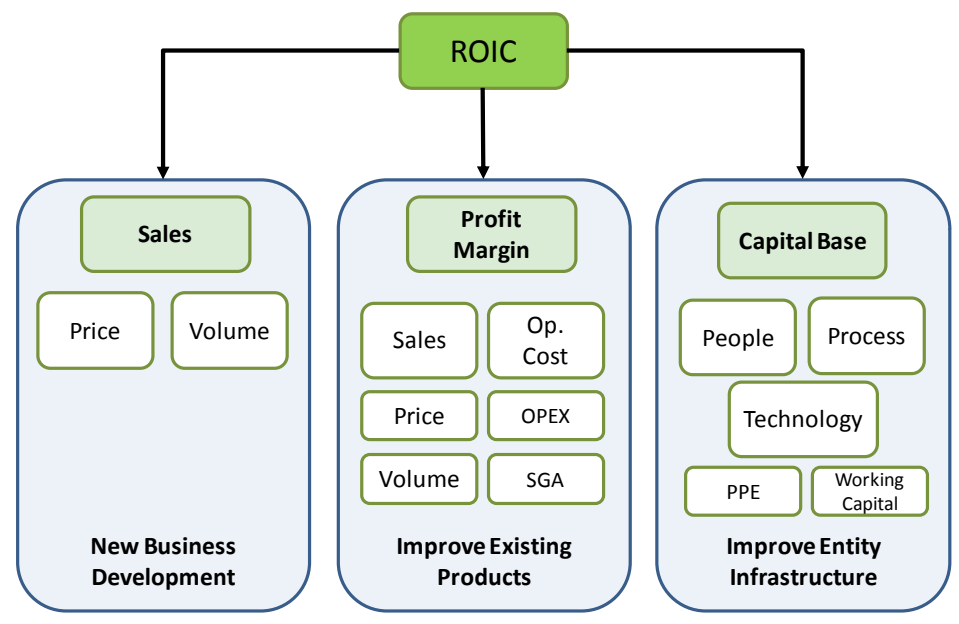

Therefore, ROIC can be increased by changing any one of the drivers mentioned above, such as increased sales through price or volume, reduction in operating costs, or more efficient use of capital employed. The strategies and mapping of drivers is given in the diagram here.

The forces that drive ROIC and therefore renewal can, for sake of illustration be mapped into three renewal strategies: new business development; improvement of existing products, or improvement of entity infrastructure. While the diagram above maps each driver to its corresponding strategy, it is possible for one strategy to affect more than one driver. For example, changing the price of a product could affect volume and working capital. (We make no claim here as to completeness; this listing of renewal forces is merely illustrative of how to employ the CFRP framework.)

To further illustrate forces of renewal, we tabulate examples of specific actions that have affected a firm's growth function, along with names of companies that have executed these activities in the past.

\begin{tabular}{|c|c|}
\hline New Business Development & Example \\
\hline $\begin{array}{l}\text { Mainstream innovation, R\&D } \\
\text { Creating valuable intellectual } \\
\text { property } \\
\text { Creating a market standard } \\
\text { Blue Oceans Strategies: Create } \\
\text { new factors that never existed } \\
\text { Cost Leadership: Minimize costs }\end{array}$ & $\begin{array}{l}\text { Apple's creation of the ipad and tablet pc } \\
\text { Merck's pharmaceutical drugs IP creation } \\
\text { Apple's App store and the corresponding network } \\
\text { effects } \\
\text { Yellow Tails conversion of wine into a new party } \\
\text { drink } \\
\text { Hyundai, Kia and other cost leader car } \\
\text { manufacturers }\end{array}$ \\
\hline
\end{tabular}

One way a company can increase its advantage and generate excess returns is by developing new businesses and products. For instance, a company would study customer, market and industry demand to determine new value propositions that are currently not being provided. The company would then use the assets it owns to provide this value proposition in a more efficient manner than any of its competitors. Doing so will allow the company to create excess returns that cannot easily be copied by its competitors.

\begin{tabular}{|l|l|}
\hline \multicolumn{1}{|c|}{ Improve Existing products } & \multicolumn{1}{|c|}{ Example } \\
\hline Speed up product development & Eli Lilly reducing time to market for Drugs \\
$\begin{array}{l}\text { Produce more attractive } \\
\text { products } \\
\text { Blue Ocean Strategies } \\
\text { Reduce factors below the industry } \\
\text { standard } \\
\text { Eliminate factors that the industry } \\
\text { takes for granted } \\
\text { Raise factors above industry } \\
\text { standard } \\
\text { Resource Leverage: Emphasize } \\
\text { high value activities } \\
\text { Economies of scale: Cost Leader } \\
\text { Reduce COGS, SG\&A }\end{array}$ & $\begin{array}{l}\text { Ford producing new model cars } \\
\text { Simplified below industry standard and geography } \\
\text { removed as industry took geography for granted }\end{array}$ \\
\hline
\end{tabular}

Another way for a company to renew its advantage is by improving existing products. This includes increasing functionality and attractiveness of the product portfolio in order to boost sales, as well as improved materials, sourcing and production in order to improve profit margin. Traditionally, a company's research and development are focused towards improving current products 
and businesses. A particularly interesting activity in improving existing products is speeding up product development and a product's time to market. Since an increase in speed of bringing a product to market would translate into more upgrades and added functionality for a product for a given unit of time.

\begin{tabular}{|l|l|}
\hline \multicolumn{1}{|c|}{ Improve Entity Infrastructure } & \multicolumn{1}{c|}{ Example } \\
\hline $\begin{array}{l}\text { Mergers and Acquisitions } \\
\text { Superior Human Resources } \\
\text { management } \\
\text { IT systems implementation }\end{array}$ & $\begin{array}{l}\text { Cisco's acquisition of several smaller } \\
\text { telecommunication companies }\end{array}$ \\
Capital Projects & $\begin{array}{l}\text { Walmart integrated 5K different IT systems across } \\
\text { the globe } \\
\text { Noble Drilling upgraded 10 ships in its fleet }\end{array}$ \\
$\begin{array}{l}\text { Resource Leverage } \\
\text { Accessing the resource of partners } \\
\text { Combining Skills in new ways } \\
\text { Minimizing time to payback }\end{array}$ & \\
\hline
\end{tabular}

The third category of renewal strategies concerns improving the efficiency of the company's asset base. Increased efficiency can come from improvements in people, processes and/or technologies. Some of the activities that constitute this category are mergers and acquisitions, IT implementations, and capital technology projects. Each of the above activities affects people, processes or technology that affects the capital efficiency of the company.

An, additional, fourth way of creating renewal in a company is by changing the rules of the game. The ability to change the rules creates at temporary monopoly power for a company: the company's ability to effectively control demand, supply and price, thereby making itself an exclusive market maker in the industry. One popular framework that illustrates this is that of the Blue Ocean strategy (Kim and Mauborgne 2005).

\section{FIRM CONVERGENCE AND STRATEGY}

As mentioned above, forces that drive a firm's decay function are present in both the renewal period and the convergence period. This decay function reduces the excess returns (ROIC $-\mathrm{C}$ ) generated by a project. In the renewal period, forces of renewal overcome forces of convergence to grow excess returns. However, the convergence period is characterized by the absence of sufficient renewal forces. Therefore, the forces of convergence drive the decay function to reduce excess returns of the project over the remainder of project life.

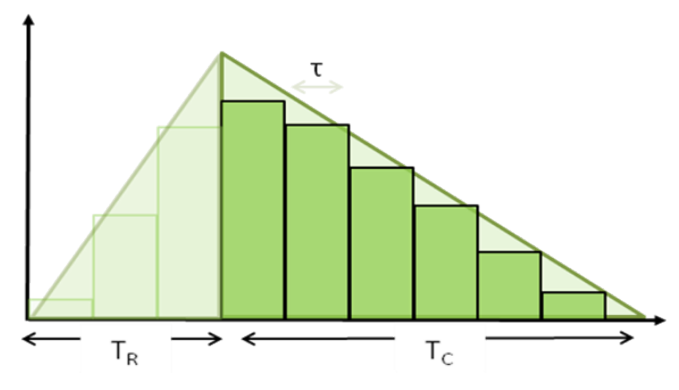

Again, for simplicity we assume that (ROIC - C) decreases at a constant rate over time and therefore can be modeled as a linear equation, with $y$-intercept $c$ and slope $M_{c} . M_{c}$ is the rate of decay of excess returns $(\mathrm{ROIC}-\mathrm{C})$.

Using equation of a line $y=m x+C$, y can be rewritten as excess returns $=(\mathrm{ROIC}-\mathrm{C})$ and substituting into the above equation we get:

$(R O I C-C)=c-M_{c} t$

The value for $y$ intercept $\mathrm{c}$ can be defined as the excess return earned by when $t=T_{R}$ therefore: 
$R O I C-C=(R O I C-C)_{\max }-M_{c} t$

At $\mathrm{T}=\mathrm{T}_{\mathrm{R}}+\mathrm{T}_{\mathrm{C}}$, ROIC $-\mathrm{C}=0$. Rewriting the above equation for $\mathrm{M}_{\mathrm{c}}$, between time periods $\mathrm{T}=$ $\mathrm{T}_{\mathrm{R}}$ and $\mathrm{T}=\mathrm{T}_{\mathrm{R}}+\mathrm{T}_{\mathrm{C}}$ :

Decay function, $\mathrm{M}_{\mathrm{c}}=M_{c}=\frac{(R O I C-C)_{\max }}{T_{C}}$

This can thought of as the rate of decay of excess returns over time or the firm's decay function. Mathematically this can be shown in the following manner:

$1^{\text {st }}$ Derivative:

$\frac{d y}{d t}=\lim _{\Delta t \rightarrow \infty} \frac{\Delta y}{\Delta t}=\lim _{\Delta t \rightarrow \infty} \frac{(R O I C-C)_{\max }-M_{c}(t+1)-(R O I C-C)_{\max }-M_{c}(t)}{\Delta t}$

$\lim _{\Delta t \rightarrow \infty} \frac{-M_{c} \Delta t}{\Delta t}=-M_{c}$

As $\Delta \mathrm{t}$ approaches $0,-\mathrm{M}_{\mathrm{c}}$ becomes the first derivative of excess returns with respect to time.

$\mathrm{M}_{\mathrm{c}}$ can be thought of as the ratio of two opposing forces whose relative strength determines the convergence period $\mathrm{T}_{\mathrm{C}}$. The two forces are: (1) the convergence forces that cause a systematic erosion of a firm's ability to generate excess returns (ROIC $-\mathrm{C}$ ) to zero, and (2), the isolating mechanism force that is trying to maintain a firm's ability to generate excess returns.

The convergence force can be described as the cumulative effect of all rival competitive reactions to actions of renewal taken on by the firm. As stated by Barnett (1996), competition amongst firms evolves through a self reinforcing circular process in which successful improvements in a firm are "learnt" or trigger improvements in rival firms thereby negating the impact of the original firm's improvement over time. Consequently, convergence force can be described as all the renewal actions taken on by rival firms to increase their respective ability to generate excess returns (ROIC - C). The strength of the industry's convergence force can be dictated by the cumulative strength of individual rival firm's forces of renewal and individual rival firm's past and future competitive learning forces. While the net effect of this convergence force is to erode all excess returns of the firm (and ultimately, the industry) to zero, the strength of rival firm's renewal forces and competitive learning forces determine the time it takes to erode excess returns, convergence time, $\mathrm{T}_{\mathrm{C}}$.

Isolating mechanisms are unique, non-reproducible resources that increase the costs associated with a rival firm's ability to either learn from competition or to create renewal (Rumelt, 1984). Williams (1992), postulates that all firms in all industries eventually lose their competitive advantage. However what differs is the length of time, from firm to firm, that it takes for this to happen. Williams suggests that a key driver behind different convergence times is due to the presence of isolating mechanisms of varying strength. This paper employs a similar definition of isolating mechanisms. The isolating mechanism force can be considered the force that is counteracting the convergence force thereby attempting to extend the competitive advantage of the firm. The isolating mechanism force can be regarded as the summation of all the isolating mechanisms that help a firm maintain its advantage over competition. It is important to note that although the isolating mechanism force and the original isolating mechanism, as defined by 
Rumelt (1984), behave similarly; the final net effect is different. Rumelt's isolating mechanisms provide a stable competitive advantage indefinitely till unpredictable changes in the firm, industry or environment changes those isolating mechanisms. Our approach, then, is that isolating mechanisms, no matter how strong, will eventually be eroded by competitive actions within the industry.

Thus, the convergence force works to increase the slope $\mathrm{M}_{\mathrm{c}}$ or decay function, thereby reducing the convergence time $T_{C}$ while the isolating mechanism force counteracts the convergence force, decreasing the slope $M_{c}$ and increasing convergence time.

Mathematically: $\mathrm{M}_{\mathrm{c}}=\mathrm{C}_{\mathrm{f}} / \mathrm{IM}_{\mathrm{f}}$

Where $\mathrm{C}_{\mathrm{f}}$ is the Convergence force and $\mathrm{IM}_{\mathrm{f}}$ is the isolating mechanism force.

The diagram below demonstrates the effect of changes in the magnitude of the components of the decay function on the convergence time $\mathrm{T}_{\mathrm{C}}$. The convergence force has a clockwise direction and is trying to move the excess return line in a clockwise direction. Any clockwise movement of the excess return line will result in a reduction in convergence time, $\mathrm{T}_{\mathrm{C}}$. The isolating mechanisms force has a counter clockwise direction and is trying to move the excess return line in a counter clockwise direction. A counter clockwise movement of the excess return line will increase the convergence time, $T_{C}$. Therefore the relative strength of the isolating mechanism force present in

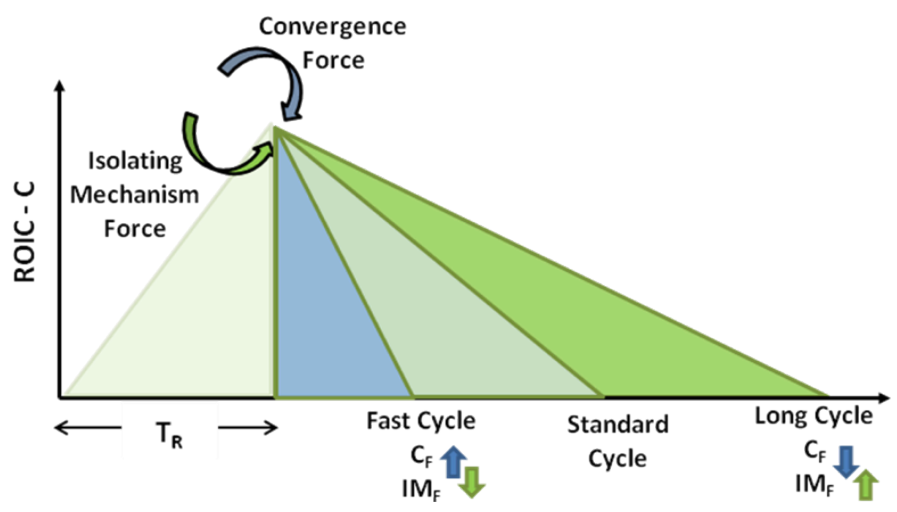

isolating mechanisms in this context follows below.) the firm, relative to the strength of the convergence forces, dictates the convergence time of the firm operating in a given industry. This thought is aligned to William's competitive cycles' framework where firms extend their competitive advantage through the use of strong isolating mechanisms. Isolating mechanisms are firm specific and firms can employ strategies to increase the number and strength of these isolating mechanisms. (Further discussion of

The second force that defines the decay function $\mathrm{M}_{\mathrm{c}}$, the convergence force, is independent of the firm and mostly out of the control of each individual firm. As described above, the convergence

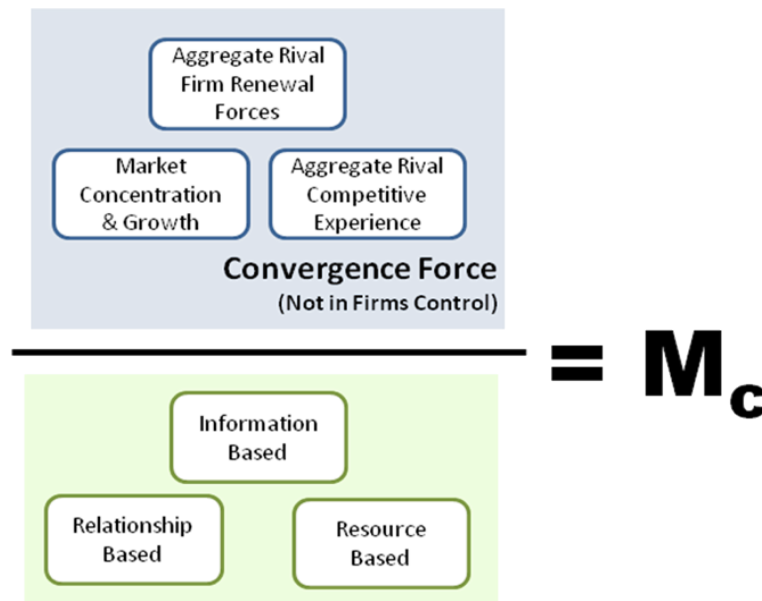

Isolating Mechanism Force force is composed of aggregate renewal forces of individual firms and competitive learning effects of rival firms. Barring isolating mechanisms, the firm has no control over rival actions of renewal and thus rival renewal forces. Competitive learning can be described by past competitive experience of rival firms (Barnett 1996), and future competition intensity defined by industry concentration and market growth (Derfus 2008). As was in the case of renewal, the firm has little control over its rival's competitive learning 
experience or its industry's competitive intensity. We therefore focus our paper on the isolating mechanism force that is firm specific and under the control of the firm. We also emphasize again that the examples that follow vary by firm and are presented for illustrative purposes.

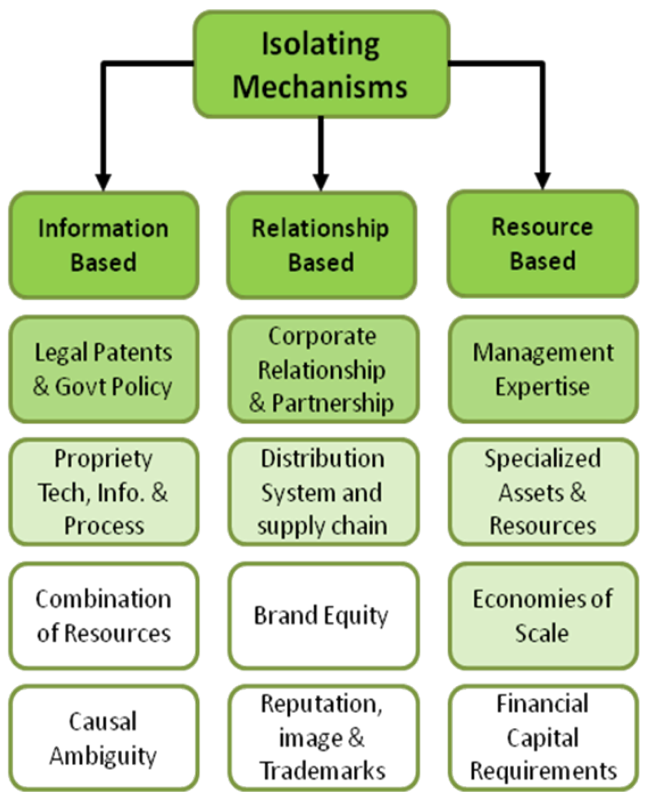

Isolating mechanisms can be classified based on their type. We classify isolating mechanisms into three broad categories: Information based, relationship based, and resource based. Information based isolating mechanisms are developed by using different forms of intellectual capital that cannot, or require significant effort to be duplicated. Patents are legal protection from duplication and provide a strong form of competitive isolation. Similar isolating mechanisms such as unique combination of resources and Rumelt's causal ambiguity exist due to knowledge possessed by the firm. Although proprietary technology, processes, and information are protected, they can be duplicated through reverse engineering and research and development efforts.

Relationship based isolating mechanisms are created by the formation of special relationships by the firm that have an adverse effect on the operations of rival firms. Corporate relationships between client firms and consulting companies are one such example. These customer relationships create customer entrenchment thereby creating firm-specific barriers to rival firms. Supply chain relationships that allow for monopolistic control over a unique distribution channel increases the cost of rival firms to operate. Brand loyalty, reputation and image are relationship-based links between the firm and its customer.

The last category is resource based isolating mechanisms. The presence of unique and immobile resources, either in type or quantity, provides a defensible competitive advantage for the firm. For example, management expertise is a unique and non-duplicating resource available to a firm. The strength of the above isolating mechanisms lies in the fact that it is highly unlikely that a rival firm would or even could purchase all the senior management expertise of the firm. Economies of scale is a resource based isolating mechanism whose scale of operations gives the firm a cost advantage that adversely affects rival firms.

Although we consider renewal and convergence forces to be distinct, in practice, they can be combined. Economies of scale affect both renewal forces as well as convergence forces. As a renewal force, economies of scale increases the profit margin of a company through lower costs that improve ROIC. However, the additional power of economies of scale lies in its behavior as an isolating mechanism. If a company can achieve unparalleled economies of scale in the industry, it will have the lowest cost structure and it will increase the cost of its competitors to compete. 
In summary, as compared to earlier assumptions of a constant cash flow generation, or generation of excess ROIC for a static period of time $\mathrm{T}$, cyclical variations of excess ROIC to perpetuity can now be assumed and managed accordingly. This cyclical nature is modeled by a simple saw tooth function comprised of two specific sets of competitive time: renewal time $T_{R}$ and convergence time $T_{C}$ that together sum up to the total cash flow recovery period $T . T_{R}$ is the time period during which the company grows its excess returns $\left(\mathrm{ROIC}-\mathrm{C}\right.$ ) despite competitive forces, whereas $\mathrm{T}_{\mathrm{C}}$ is the time period when the renewal forces cease to exist, therefore, creating a reduction of excess returns of the company.

Therefore the value the generated by the firm is dependent on three variables; renewal time $T_{R}$, convergence time $T_{C}$ and maximum magnitude of excess return (ROIC $-\mathrm{C}$ ). The firm should choose renewal strategies that maximize the benefits from each of these variables. Thus, when choosing renewal strategies, the firm should also consider the development of isolating mechanisms that can prolong the competitive advantage of renewal strategies by lengthening convergence time $\mathrm{T}_{\mathrm{C}}$. Firms with a proven record of excelling in these three dimensions would have a higher perpetuity valuation.

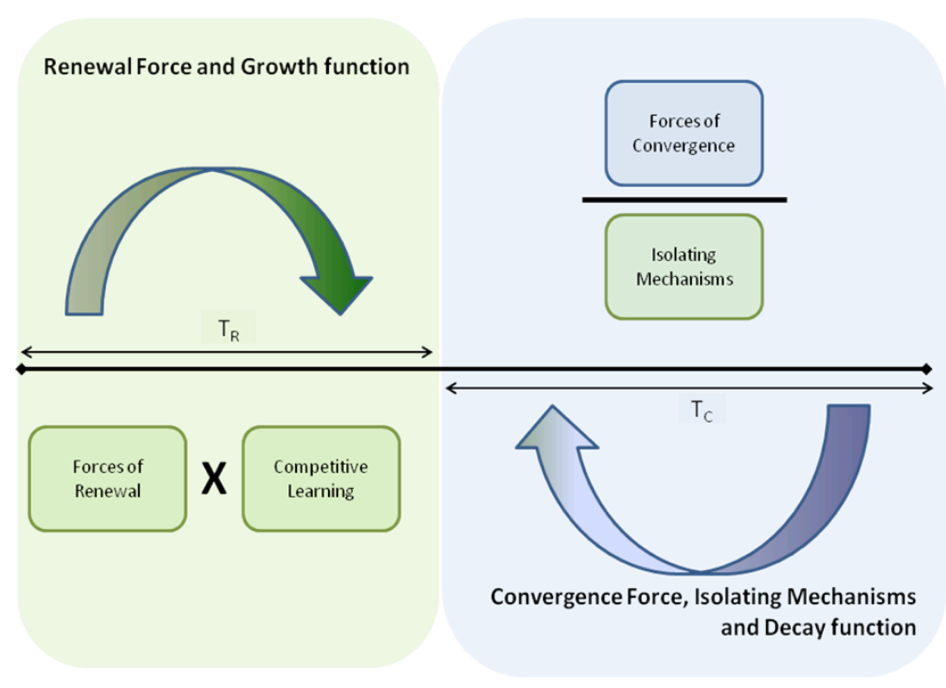

\section{ADJUSTING EVA FOR RENEWAL AND CONVERGENCE}

Now that we have developed a strategic framework that incorporates cash flow recovery period (CFRP) and associated strategies, we can develop a set of adjustments to an EVA equation that will allow us to value a firm or a project based on CFRP perpetuity assumptions. The equation developed will have to account for cyclical variations of (ROIC - C) as well as being appropriately discounted to account for the time value of money.

As before, the equation is calculated by dividing each competitive cycle into two periods, a renewal period and a convergence period. For each period, we determine the equation of the line that tracks EVA during the renewal period and convergence period respectively. For each given time period in a competitive cycle, we are able to determine the excess return (ROIC $-\mathrm{C}$ ) 
generated by the firm, thereby calculating the amount of EVA generated within that year. Calculating that up to perpetuity we are able to come up with the following formula ${ }^{\text {ii }}$.

$V_{C F R P}=N O A+I(R O I C-C)_{\max } C F R P_{\text {multiple }}$

CFRP multiple $=(2+C)\left[T_{R}+T_{C}(1+C)^{T_{R}+T_{C}}-(1+C)^{T_{C}}\left(T_{R}+T_{C}\right)\right] 2 T_{R} T_{C} C^{2}\left[(1+C)^{T_{R}+T_{C}}-1\right]$

$\mathrm{V}_{\mathrm{CFRP}}=$ Enterprise value calculated using EVA over entire life

NOA $=$ Net Operating Assets

$\mathrm{I}=$ Investment Amount

ROIC $=$ Return on Invested Capital

$\mathrm{C}=$ Cost of Capital

$\mathrm{T}_{\mathrm{R}}=$ Renewal Period

$\mathrm{T}_{\mathrm{C}}=$ Convergence Period

$\mathrm{CFRP}_{\text {multiple }}=$ Cash Flow Recovery Period Multiple

The key take away from the above equation is the adjustment " $\mathrm{CFRP}$ multiple" or cash flow recovery period multiple. This one term accounts for adjustments made due to cyclical nature of competition as well as time value of money. For a detailed derivation of the equations please look at the appendix. The effect of the CFRP ${ }_{\text {multiple }}$ on firm valuation can be easily understood. For a given maximum excess return value $(\mathrm{ROIC}-\mathrm{C})$, a higher $\mathrm{CFRP}_{\text {multiple }}$ indicates higher valuation for a firm and a lower $\mathrm{CFRP}_{\text {multiple }}$ indicates a lower valuation for a firm.

This multiple, depends on $\mathrm{T}_{\mathrm{R}}$, time for renewal, $\mathrm{T}_{\mathrm{C}}$, time for convergence and $\mathrm{C}$, cost of capital.

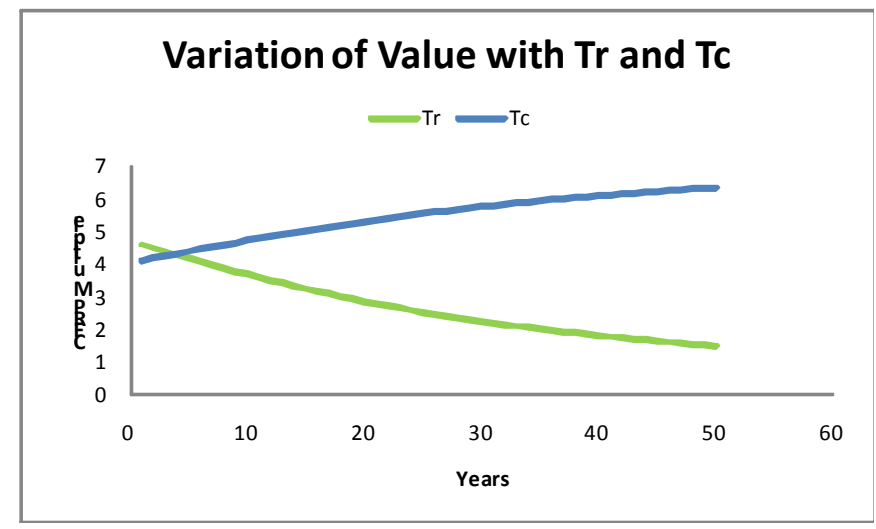

The chart above simulates the effect of increased time for renewal and time for convergence on the CFRP multiple. The $y$-axis in the chart above is the CFRP ${ }_{\text {multiple }}$ while the $\mathrm{x}$-axis corresponds to units of time, denoted above in years. The green line illustrates the effect of increasing the time

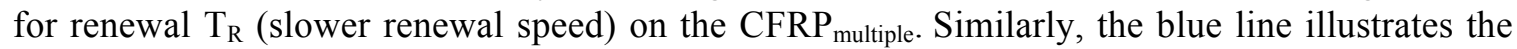
effect of increasing the time for convergence $\mathrm{T}_{\mathrm{C}}$ (slower convergence speed) on the $\mathrm{CFRP}_{\text {multiple }}$.

The first key takeaway that the diagram illustrates is the intuition about the nature of convergence time and renewal time and their effect on valuation. An increase in renewal time (green line), that is, a slower growth function, decreases the CFRP multiple. This logic is intuitive, as one would prefer a project to be able to reach its maximum excess returns as fast as possible, assuming 
similar maximum cash flow levels across projects. Similarly, an increase in convergence time (blue line), that is, a slower decay function, increases the valuation multiple. This logic is also intuitive as one would prefer a project that can more effectively protect its competitive advantage and thereby continue to generate excess returns as long as possible.

The second key takeaway the diagram illustrates has to do with the rate of increase or decrease of the $\mathrm{CFRP}_{\text {multiple. }}$. One can see from the graph that Tc needs to change by a factor of 10 years while $\operatorname{Tr}$ needs to change by a factor of 13 years to bring about a change to the $\mathrm{CFRP}_{\text {multiple }}$ by a factor of 1. For example, changing Tc from 0.5 years to 10 years increases the corresponding $\mathrm{CFRP}_{\text {multiple }}$ from 4 to 5 . Additionally, the effect on $\mathrm{CFRP}_{\text {multiple }}$ by changing either $\mathrm{Tr}$ or $\mathrm{Tc}$ follows a diminishing curve (the exact shape of the $\mathrm{Tr}$ and $\mathrm{Tc}$ lines are sensitive to the assumptions chosen). Of all these assumptions, the CFRP multiple is most sensitive to the cost of capital, as might be expected ${ }^{\text {ii }}$.

The second set of analysis was done to determine the difference in accuracy between the traditional method using the perpetuity assumption and the $\mathrm{CFRP}_{\text {multiple }}$ method by comparing the time dependent multiple in both equations. For the perpetuity assumption, an EVA calculation was created based out of a given set of assumptions. Specifically, we assumed that a project would be earn a constant excess returns $(\mathrm{ROIC}-\mathrm{C})_{\mathrm{K}}$ forever up to perpetuity. Therefore the equation becomes:

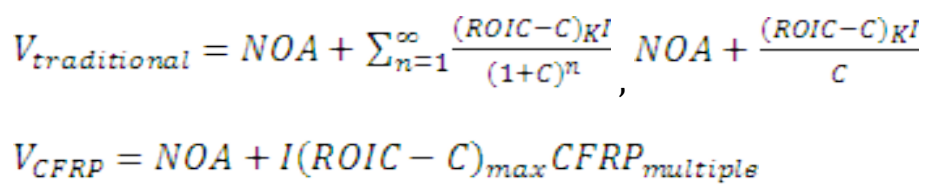

$\mathrm{V}_{\mathrm{CFRP}}=$ Enterprise value calculated using EVA over entire life

$\mathrm{NOA}=$ Net Operating Assets

ROIC $=$ Return on Invested Capital

$\mathrm{I}=$ Investment Amount

$\mathrm{C}=$ Cost of Capital

$(\text { ROIC-C })_{\max }=$ Maximum excess return

$(\mathrm{ROIC}-\mathrm{C})_{\mathrm{K}}=$ Constant Excess return

$\mathrm{CFRP}_{\text {multiple }}=$ Cash Flow Recovery Period Multiple

Additionally, since the objective of this analysis was aimed towards the perpetuity valuation, we adjusted our assumption for $(\mathrm{ROIC}-\mathrm{C})_{\mathrm{K}}$ so that the amount of EVA generated in a single cash flow recovery period $\left(\mathrm{T}_{\mathrm{CFRP}}\right)$ is equal in both methods.

For a given investment amount I, EVA is (ROIC - C) x $\mathrm{T}$ (time period), it can thought of as the area under the excess return curve $(\mathrm{ROIC}-\mathrm{C})$. Therefore:

Area under Traditional Method $=$ Area under CFRP Method

$$
(R O I C-C)_{K} \times T=\frac{(R O I C-C)_{\max } \times T}{2}
$$

Hence $2(\text { ROIC }-\mathrm{C})_{\mathrm{K}}=(\text { ROIC }-\mathrm{C})_{\max }$ Putting this in the equation above:

$$
V_{\text {traditional }}=N O A+I \frac{(R O I C-C)_{K}}{C}
$$


$V_{C F R P}=N O A+I(R O I C-C)_{K}\left(2 \times C F R P_{\text {multiple }}\right)$

Therefore, a change in $\mathrm{T}_{\mathrm{R}}$ or $\mathrm{T}_{\mathrm{C}}$ will affect $\mathrm{V}_{\mathrm{CFRP}}$ but will have no effect on $\mathrm{V}_{\text {traditional. }}$ In order to quantify this effect, we generated a sensitivity table with a given a cost of capital of $12 \%$.

\begin{tabular}{|c|c|c|c|c|c|c|c|c|c|c|}
\hline$T R \backslash T C$ & 3.0 & 4.0 & 5.0 & 6.0 & 7.0 & 8.0 & 9.0 & 10.0 & 11.0 & 12.0 \\
\hline 1.0 & 8.6291 & 8.7758 & 8.9215 & 9.0661 & 9.2093 & 9.3511 & 9.4912 & 9.6295 & 9.7659 & 9.9003 \\
\hline 2.0 & 8.4452 & 8.5827 & 8.7191 & 8.8541 & 8.9877 & 9.1197 & 9.2499 & 9.3783 & 9.5047 & 9.6291 \\
\hline 3.0 & 8.2628 & 8.3915 & 8.5189 & 8.6449 & 8.7693 & 8.8920 & 9.0129 & 9.1319 & 9.2489 & 9.3638 \\
\hline 4.0 & 8.0820 & 8.2023 & 8.3211 & 8.4385 & 8.5541 & 8.6681 & 8.7802 & 8.8903 & 8.9984 & 9.1045 \\
\hline 5.0 & 7.9030 & 8.0152 & 8.1260 & 8.2351 & 8.3425 & 8.4482 & 8.5520 & 8.6538 & 8.7536 & 8.8514 \\
\hline 6.0 & 7.7261 & 7.8306 & 7.9336 & 8.0350 & 8.1347 & 8.2325 & 8.3285 & 8.4225 & 8.5145 & 8.6045 \\
\hline 7.0 & 7.5513 & 7.6486 & 7.7443 & 7.8383 & 7.9306 & 8.0211 & 8.1097 & 8.1964 & 8.2812 & 8.3640 \\
\hline 8.0 & 7.3789 & 7.4693 & 7.5581 & 7.6452 & 7.7306 & 7.8142 & 7.8959 & 7.9758 & 8.0537 & 8.1298 \\
\hline 9.0 & 7.2090 & 7.2929 & 7.3752 & 7.4558 & 7.5347 & 7.6118 & 7.6871 & 7.7606 & 7.8322 & 7.9020 \\
\hline 10.0 & 7.0418 & 7.1196 & 7.1958 & 7.2702 & 7.3430 & 7.4141 & 7.4834 & 7.5509 & 7.6166 & 7.6806 \\
\hline
\end{tabular}

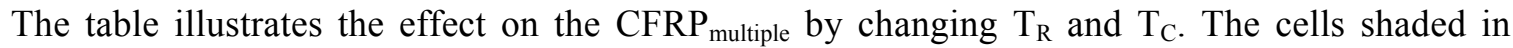
green are those $C F R P_{\text {multiple }}$ values that are greater than the traditional perpetuity multiple $(1 / C)$. Similarly, the cells shaded in red identify those values where the CFRP multiple $_{\text {is }}$ less than the traditional perpetuity multiple. Since the only difference in the two valuation methods is the time multiple, one can infer that those scenarios shaded in green have a higher valuation using the CFRP method while the scenarios shaded in red have a higher valuation using the traditional method ${ }^{\text {ii }}$.

The main take away from this analysis is that the CFRP ${ }_{\text {multiple }}$ method adds another level refinement in the valuation methodology by explicitly considering both the numerical and strategic effects of $T_{R}$ and $T_{C}$. All else constant, for a given cost of capital, the traditional perpetuity method would give a single valuation. The CFRP $\mathrm{P}_{\text {multiple }}$ method would give a range of valuations that may be higher or lower than the traditional method, based on principles of cash flow recovery period strategies. Therefore the CFRP valuation methodology, by taking into account time for renewal and time for convergence offers the potential for more accuracy than the traditional perpetuity method.

Additionally, to illustrate the difference between the valuation done using a traditional DCF and the adjusted EVA equation, a simulation was constructed, with the only difference between the two models being the method in which growth was forecasted. In the traditional DCF model, an initial growth of $20 \%$ was assumed that declines each year by $5 \%$ until it reached $0 \%$ in 5 years. For the EVA adjusted model, we used a starting ROIC that equalized the initial NOPAT for both models. Forecasts in ROIC were then made in accordance with the cash flow recovery period concept. A maximum economic profit of $10 \%$ was chosen with a renewal time of 2 years and convergence time of 7 years. The result of this valuation is given below ${ }^{\mathrm{ii}}$ :

\begin{tabular}{|llr|}
\hline DCF & Enterprise Value & $\$ 7,905.2$ \\
& Equity Value & $6,905.2$ \\
& Price / Share & $\$ 69.1$ \\
& & \\
\hline
\end{tabular}

\begin{tabular}{|llr|}
\hline EVA & Beginning Capital & $\$ 5,000.0$ \\
& Sum EVA & $2,374.1$ \\
& Enterprise Value & $7,374.1$ \\
& Equity Value & $6,374.1$ \\
& Price / Share & $\$ 63.7$ \\
\hline
\end{tabular}

The above results indicate that while both methods deliver similar valuation results, the difference between them is about $7 \%$. To this degree, the adjusted valuation method provides a potentially 
more robust valuation that takes into account - and encourages strategies to maximize - the distinctive renewal and convergence forces for a project.

\section{CONCLUSION}

The benefit of the cash flow recovery period framework introduced in this paper is that the assumptions derived are in line with how competitive markets operate. This syncing of valuation and competitive forces has useful implications for cash flow forecasting and the management of project cash flows. Instead of relying on perpetuity growth rates, crude forecasts, or static time assumptions, more dynamic and precise cash flow recovery estimates can be calculated based on actions controllable by the firm and the state of affairs governed by competitive conditions.

A point to note is that both excess returns $(\mathrm{ROIC}-\mathrm{C})$, as well as cash flow recovery period $\mathrm{T}$ are historically measurable. Therefore, the decay function $\mathrm{M}_{\mathrm{c}}$ and the ratio of the convergence force and isolating mechanisms force are also measurable. By measuring these historically for different industries, one can further study and analyze the relative effects of these forces for different industries over time. $T_{R}$ and $T_{C}$ are also readily measurable for a company and can be aggregated for an industry. Based on these values, one can extrapolate historical decay and growth functions and decipher a trend for these functions. Additionally, studies can be conducted to calculate higher order derivatives of these functions. Is the decay function getting more negative with time? Is the convergence force increasing for certain industries? Slowing down for others?

Overall, it is hoped that methods such as this can encourage more accurate forecasting by linking the dynamic competitive forces at work in the firm's environment to actual cash flows that result, while providing a forward-looking cause and effect explanation to forecasts that enable the user to develop executable strategies over time that enhance firm value. 


\section{REFERENCES}

1. Barnett, W. P., Morten, H. T., 1996. The Red Queen in Organizational Evolution. Strategic Management Journal, Vol. 17, 139-157

2. Christopher, M., Ryals, L., 1999. Supply Chain Strategy: Its impact on Shareholder Value. International Journal of Logistics Management.

3. Day, G., Fahey, L., 1988. Valuing Market Strategies. The Journal of Marketing. American Marketing Association, July 45-57.

4. Derfus, P. J., Maggiti, P. G., Grimm, C. M., Smith, K. G., 2008. The Red Queen Effect: Competitive Actions and Firm Performance. Academy of Management Journal, Vol.51 No.1, 6180

5. Gordon, M.J., 1959. Dividends, Earnings, and Stock Prices. The Review of Economics and Statistics. The MIT Press, May, Vol.41, 99-105.

6. Kim, W. C., Mauborgne, R., 2005. Blue Ocean Strategy, Harvard Business School Press.71-79.

7. Mauboussin, M., Johnson, P., 1997. Competitive Advantage Period "Cap", The Neglected Value Driver. Financial Management. Blackwell Publishing, Summer Vol. 26 No. 2, 67-74.

8. Miller, M.H., Modigliani, F., 1961. Dividend Policy, Growth, and the Valuation of Shares. The Journal of Business. The University of Chicago Press, October, Vol.34, 411-433.

9. Pinsent, W., Decoding DuPont Analysis. Investopedia. http://www.investopedia.com/articles/fundamental-analysis/08/dupont-analysis.asp

10. Porter, M. 1979. How Competitive Forces Shape Strategy. Harvard Business Review. July August 1997, 203-212

11. Rappaport, A., 1987. Linking Competitive Strategy and Shareholder Value Analysis. Journal of Business Strategy. Spring 58.

12. Rizzi, J. V., 1984. Capital Budgeting: Linking Financial Analysis to Corporate Strategy. Journal of Business Strategy. Spring 81.

13. Rumelt, R. P. (1984). 'Towards a strategic theory of the firm'. In R.Lamb (ed.) Competitive Strategic Management. Prentice-Hall, Englewood Cliffs, NJ, pp. 556-570.

14. Shrieves, R. E., Wachowicz, J. M., 2001. Free cash flow (FCF), economic value added (EVA), and net present value (NPV): A reconciliation of variations of discounted-cash-flow (CDF) valuation. The Engineering Economist. Vol. 46 Iss. 1 33-53.

15. Stewart, G.B., 1991. The Quest for Value: A Guide for Senior Managers. Harper Collins Publishers

16. Williams, J.R., 1992. How sustainable is your advantage? California Management Review 34(3), 29-51.

17. Williams, J.R., 1994. Strategy and the Search for Rents: The Evolution of Diversity among Firms (Chapter 8 in Rumelt et al. (1994))

18. Williams, J.R., 1998. Renewable Advantage. The Free Press. New York, NY. 


\section{ENDNOTES}

i We chose to work with the EVA framework, Stewart (1991), as it was easier to visualize the concepts of cyclical competition, renewal and convergence by measuring excess returns generated by a project. Visualization of excess returns was linear as compared to non linear graphs of NOPAT in the CFRP framework. These excess returns have been defined as return on invested capital generated in excess to the cost of capital employed (ROIC -C). Quantitatively, the value calculated using the EVA method is equivalent to the value calculated using a traditional DCF model. Stewart established this relationship in his book Quest for Value, Stewart (1991), and also Shrieves and Wachowicz (2001).

ii For more information about the derivation of the above equations, valuation models or sensitivity analysis, please contact the authors. 